Original Research Paper

\title{
Prevalence and Histopathologic Analyses of Mammary Tumors in Female Dogs in the Northeast of Algeria
}

\author{
${ }^{1}$ Zahra Gabli, ${ }^{2}$ Leila Beddar, ${ }^{3}$ Amir Agabou, ${ }^{4}$ Zouhir Djerrou and ${ }^{5}$ Edouard Gomez-Reyes \\ ${ }^{1}$ Institut des Sciences Vétérinaires, Université des Frères Mentouri-Constantine 1, Constantine, Algérie \\ ${ }^{2}$ Service d'Histologie et d'Anatomie Pathologique, Centre Hospitalo-Universitaire Ben Badis, Constantine, Algérie \\ ${ }^{3}$ Laboratoire PADESCA, Institut des Sciences Vétérinaires, Université des Frères Mentouri-Constantine 1, Algérie \\ ${ }^{4}$ Département des Sciences de la Nature de la Vie, Faculté des Sciences, Université 20 Août 1955 Skikda, Algérie \\ ${ }^{5}$ Université Paris-Est, Ecole Nationale Vétérinaire d'Alfort, \\ Unité d'Embryologie, d'Histologie et d'Anatomie pathologique, BioPôle Alfort, Maisons-Alfort, France
}

Article history

Received: 30-08-2017

Revised: 23-09-2017

Accepted: 26-09-2017

Corresponding Author:

Zahra Gabli

Institut des Sciences

Vétérinaires, Université des

Frères Mentouri-Constantine 1,

Constantine, Algérie

E-mail: zahras-com@gmail.com

\begin{abstract}
Cancers development and complications are a major cause of death in dogs all over the world. The current study attempts to describe the prevalence and anatomo-pathologic traits of mammary gland tumors (MGTs) in bitches in northeast Algeria. From November 2013 to April 2016, a total of 215 bitches originating from four provinces (Constantine, Oum El Bouaghi, Annaba and Skikda) were enrolled. The overall prevalence of MGTs was $19.53 \%$. It was higher in littoral provinces $(27.22 \%)$ than in inland ones $(15.33 \%)$. A high rate was documented in Caniche (43.75\%) as compared to Cross-breed (16.17\%) and German shepherd (14.78\%) bitches. The mean age of positively diagnosed animals was $9 \pm 0.3$ years and the mean size of tumors was $5.4 \pm 04 \mathrm{~cm}$. Histopathological classification revealed that $40.47 \%$ tumors were benign (mainly benign mixed tumors and benign complex tumors), $30.95 \%$ were malignant (especially epidermoid carcinoma, mammary sarcoma and malignant complex tumors) and $28.57 \%$ were identified as dysplasia (Mostly Osteo-mammary, benign hyperplasia and fibrocystic mastopathy). Finally, more epidemiological investigations are needed to determine the risk factors that may be implicated in the initiation and evolution of these health problems.
\end{abstract}

Keywords: Bitches, Mammary Gland, Tumors, Histopathology, Algeria

\section{Introduction}

Neoplasia is a disorder characterized by a continual unregulated proliferation of some cells which respond inappropriately to the signals that control normal cells behavior and grow/divide in an uncontrolled way. This disease strikes people as well as animals and can occur in various organs and tissues.

In dogs, Mammary Gland Tumors (MGTs) are among the most prevalent diagnosed neoplasms in the elderly unsprayed bitches (Vail and MacEwen, 2000). In these animals, the mammary gland appears to be more predisposed to develop tumors compared with other animal species (Kumar et al., 2010). Commonly, canine mammary tumors are firm, well-circumscribed nodules of few millimeters to $10-20 \mathrm{~cm}$ of diameter. The tumor itself and its covering skin may be traumatized and ulcerated (MacEwen and Withrow,
1996; Simon et al., 1996).

In general, tumors have a poly factorial etiology and their pathogenesis is still insufficiently clarified. Mutations in DNA genes often occur under the action of multiple endogenous and exogenous carcinogens and conduct to the transformation of normal cells into tumoral ones. In the genesis of canine MGTs, the implication of female sexual hormones has been well demonstrated since estrogen, progesterone and prolactin receptors were found in some canine MGTs (Rutteman and Misdorp, 1993; Geraldes et al., 2000).

Malignant MGTs are potentially life threatening and according to the extent and the location of the metastases, bitches may exhibit nonspecific clinical signs like tiredness, lassitude, weight loss, dyspnoea, cough, lymphoedema or lameness (Misdorp, 2002).

Several treatment options may be available for mammary tumors. Chemotherapy is not routinely 
performed and adjuvant chemotherapy provided only few promising results in dogs. Nowadays, surgery remains the treatment of choice, except for inflammatory carcinoma or presence of distant metastases (Henry, 2014).

It is worth noting that several plant extracts have showed promising results in cancer therapy. For instance, some oil soluble garlic compounds significantly inhibit growth or provoke death of canine MGTs cells in vitro (Sundaram and Milner, 1993).

In Algeria, there is scarce data on the size of the canine population, however the number of domestic dogs kept as pets as well as stray dogs is assumed to be expanding over the years. Accordingly, little information about many health problems encountered in these animals, especially with regard to the neoplasms is available. So, in the present survey, we attempted to describe the prevalence andanatomopathologic traits of mammary gland tumors in bitches from northeast Algeria.

\section{Materials and Methods}

\section{Animals}

The study was conducted during 30 months (November 2013 to April 2016) on canine patients originating from four provinces of the north-east of Algeria (Tow inland provinces: Constantine and Oum El Bouaghi and two littoral ones: Annaba and Skikda). Female dogs with MGTs suspicion were enrolled. They were presented at the Teaching Veterinary Clinical Service of the Institute of Veterinary Sciences-University Frères Mentouri of Constantine 1-Algeria. Information related to breed, age, reproductive history and application of any kind of exogenous hormones was collected.

\section{Tumors Tissues Collection and Histological Examination}

At the presentation, animals were examined and their general health state was evaluated (body weight and temperature, cardiac and respiratory frequencies, color of mucosa, size and consistency of lymph nodes). Locations of affected mammary glands were recorded in addition to tumor size, shape, consistency and adhesion to subjacent and/or surrounding tissues.

After general anesthesia, mastectomy of all tumoral glands was carried out following routine surgical techniques. Then tissue specimens were obtained from the largest tumoral lesion and fixed in $10 \%$ buffered formalin for 2 days then embedded in paraffin. Sections were cut at $3-4 \mu \mathrm{m}$ and stained with haematoxylin and eosin for histological analyses. In some cases biopsies were obtained by fine needle aspiration using a 22-G needle. The following elements were assessed: morphological features of tumoral cells, tumor growth pattern, mitotic activity, necrosis, edema and inflammation. Tumors were then classified according to the World Health Organization scheme for canine mammary lesions as detailed by (Hampe and Misdorp, 1974).

All experimental procedures were performed with the approval of the Ethics Committee in Animal Experimentation and the Research Ethical Committee at the Institute of Veterinary Sciences of Constantine (Algeria).

\section{Statistical Analysis}

Statistical analysis was generated using the statistical software Graph Pad Instat prism ver.6.04 (Graph Pad Software, Inc., San Diego, CA, USA. 2014).

The analysis of data was performed using descriptive statistics. The distribution of ages and tumor sizes was assessed using the D'Agostino test then ANOVA tests (followed by Tukey's post hoc) were applied to compare the disparities in ages and tumors sizes between the different breeds and tumor types. $X^{2}$ trend analyses were used to assess the associations between the presence of MGTs and the breed, age groups or the geographic area.

The difference was considered as statistically reliable at $\mathrm{p}<0.05$ and $95 \% \mathrm{CI}$.

\section{Results}

During the study period a total of 215 bitches were enrolled. All were not spayed and didn't receive any kind of hormonal treatment. As shown in Table 1, they belonged exclusively to 3 breeds: German shepherd, Caniche and Cross-breed. Some Macroscopic aspects and localization of some tumors were elucidated in Fig. (1-8).

\section{Prevalence and Distribution of Mammary Tumors}

The overall prevalence of MGTs in the whole studied canine population was $19.53 \%$. It was higher in littoral provinces $(27.22 \%)$ than in inland ones $(15.33 \%)$, but not in a significant manner $\left(X^{2}, p=0.070\right)$. A significant difference $\left(X^{2}, p=0.049\right)$ was observed between the provinces (Skikda: 30\%; Annaba: 24.44\%; Oum El Bouaghi: $16.66 \%$ and Constantine 15\%); but, no effect $\left(X^{2}, p=0.54\right)$ of breed on the frequency of MGTs was recorded even though a high rate was documented in Caniche (43.75\%) as compared to Cross-breed (16.17\%) and German shepherd (14.78\%) bitches.

The average age of positively diagnosed animals was $9 \pm 0.3$ years old and those aged of more than 9 years old were the most touched by this problem. There was no differences between the age of animals in regard to their breed ( $A N O V A, p=0.95)$. 
Table 1. Distribution of the sampled canine population and its characteristics

\begin{tabular}{lllll}
\hline Province & Breed & Animals enrolled Nbr & Positive Nbr (\%) & Age Mean \pm SEM (years) \\
\hline Constantine & German shepherd & 40 & $6(15)$ & $8.66 \pm 0.71$ \\
& Caniche & 9 & $4(44.44)$ & $8.25 \pm 1.31$ \\
& Cross-breed & 31 & $2(6.45)$ & $9.5 \pm 0.5$ \\
Oum El Bouaghi & Sub-total (\%) & 80 & $12(15)$ & $8.66 \pm 0.54$ \\
& German shepherd & 35 & $4(11.42)$ & $8.75 \pm 1.1$ \\
& Caniche & 11 & $3(27.27)$ & $10 \pm 1.52$ \\
Annaba & Cross-breed & 14 & $3(21.42)$ & $8 \pm 1.15$ \\
& Sub-total (\%) & 60 & $10(16.66)$ & $8.9 \pm 0.69$ \\
& German shepherd & 25 & $4(16)$ & $9.5 \pm 1.19$ \\
Skikda & Caniche & 7 & $4(57.14)$ & $8.75 \pm 1.75$ \\
& Cross-breed & 13 & $3(23.07)$ & $8 \pm 1.52$ \\
& Sub-total (\%) & 45 & $11(24.44)$ & $8.81 \pm 0.69$ \\
& German shepherd & 15 & $3(20)$ & $10 \pm 0.57$ \\
Overall & Caniche & 5 & $3(60)$ & $9 \pm 1$ \\
& Cross-breed & 10 & $3(30)$ & $10.33 \pm 1.2$ \\
Total /Overall mean (\%-Age) & Cross-breed & 68 & $9(30)$ & $9.77 \pm 0.52$ \\
& Sub-total (\%) & 30 & $17(14.78)$ & $9.11 \pm 0.44$ \\
& German shepherd & 115 & $14(43.75)$ & $8.92 \pm 0.59$ \\
& Caniche & 32 & $11(16.17)$ & $8.9 \pm 0.62$ \\
\hline
\end{tabular}

Macroscopic aspect and localization of some tumors

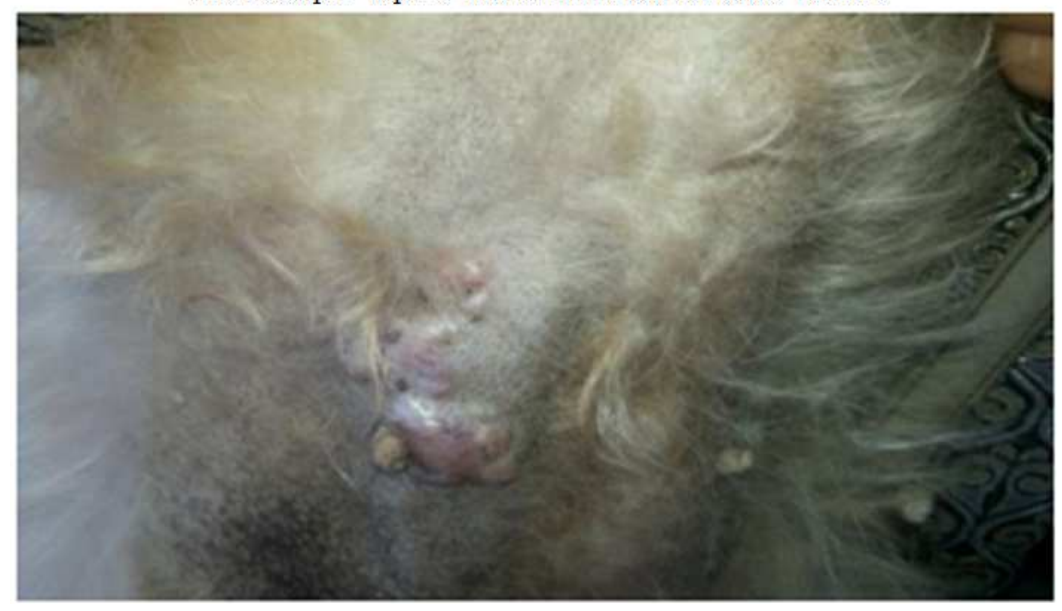

Fig. 1. Small inflamed nodule (Poodle)

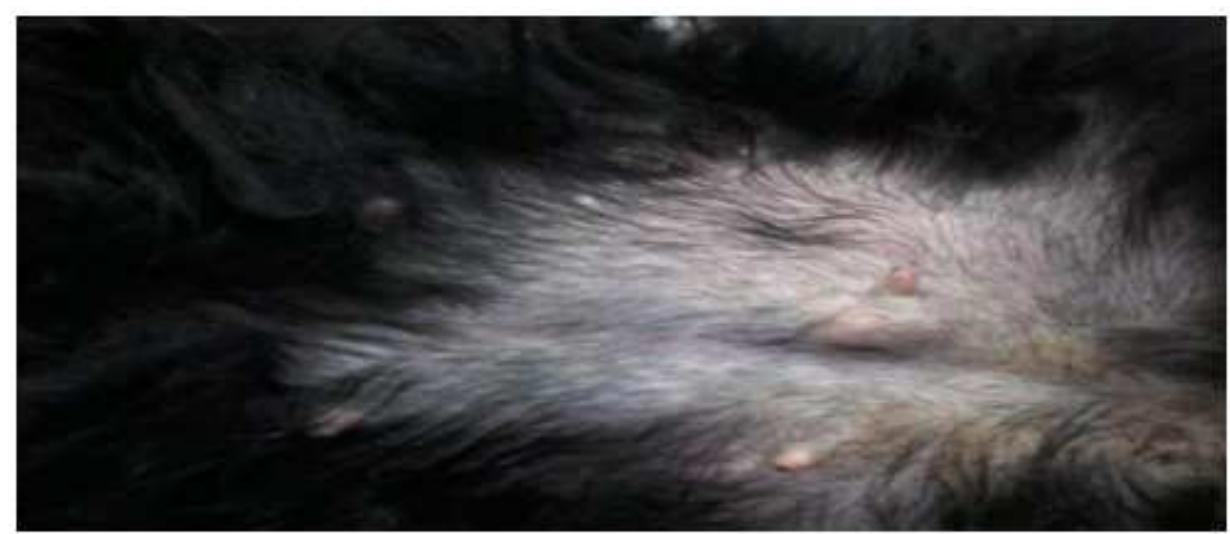

Fig. 2. Small nodule of cystic aspect (Poodle) 


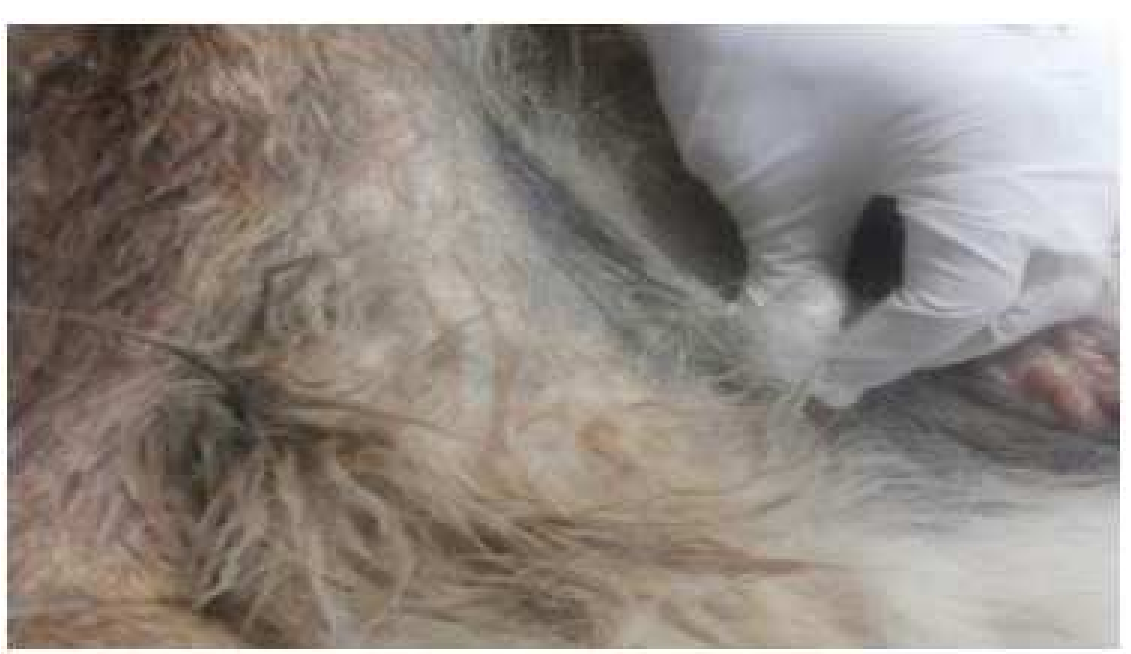

Fig. 3. Small nodule, with soft consistency (German Shepherd)

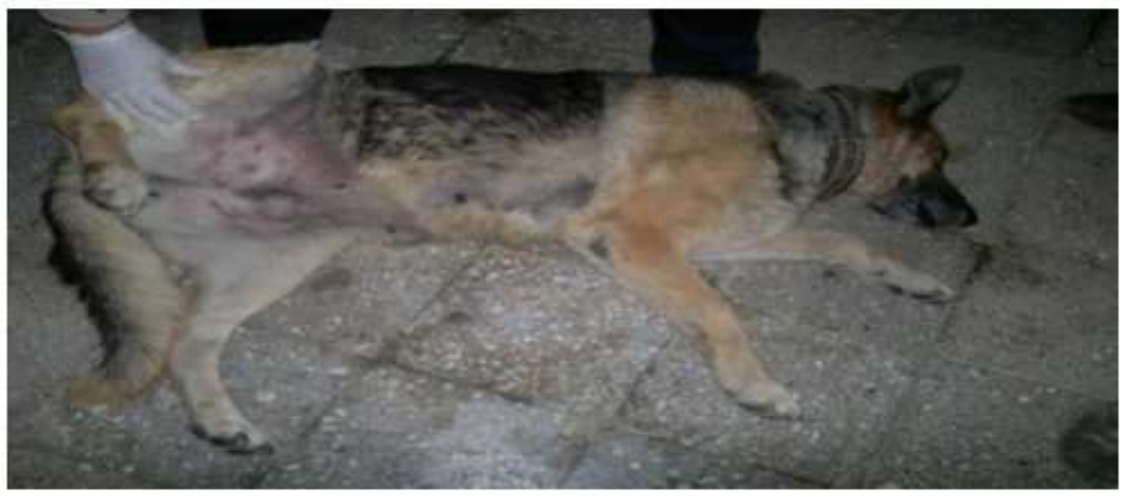

Fig. 4. Multiple nodule of soft consistency (German Shepherd)

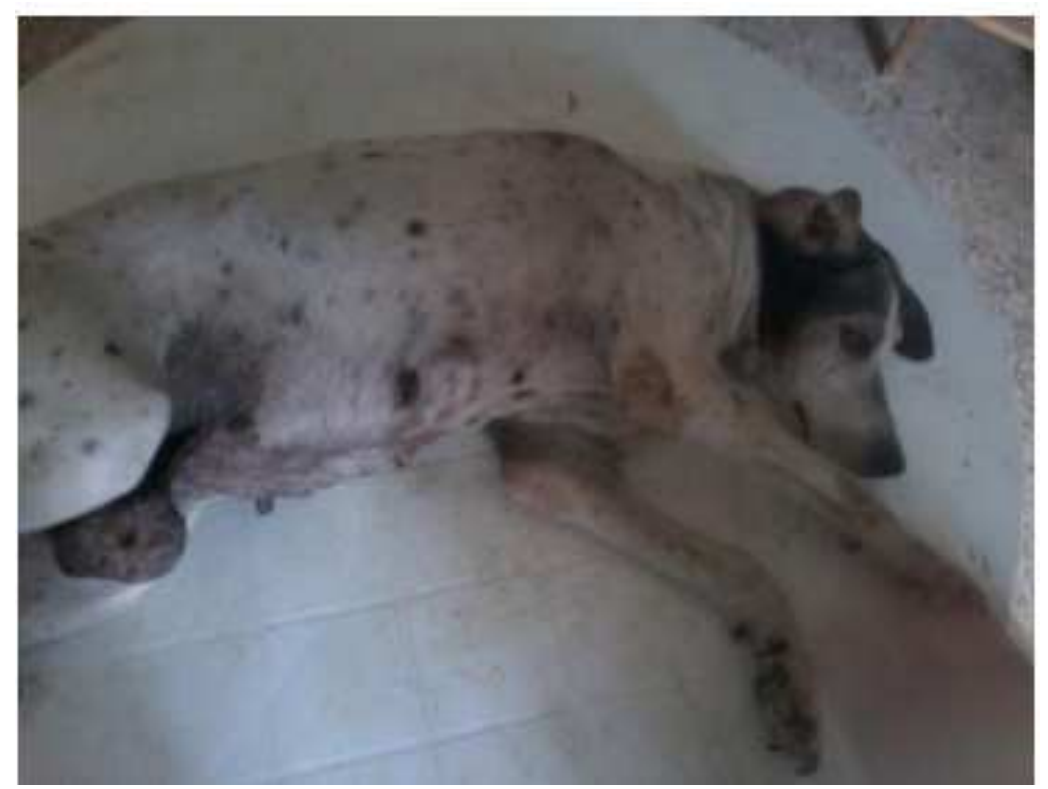

Fig. 5. Mass of hard aspect and firm (Cross-breed) 


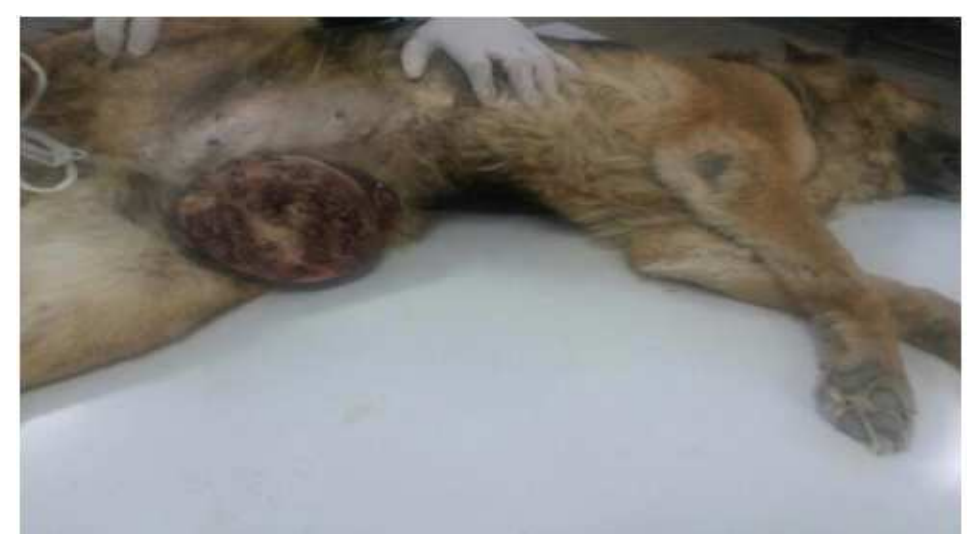

Fig. 6. Bulky mass of appearance buds, budded, ulcers, inflamed and of consistency lasts (German Shepherd)

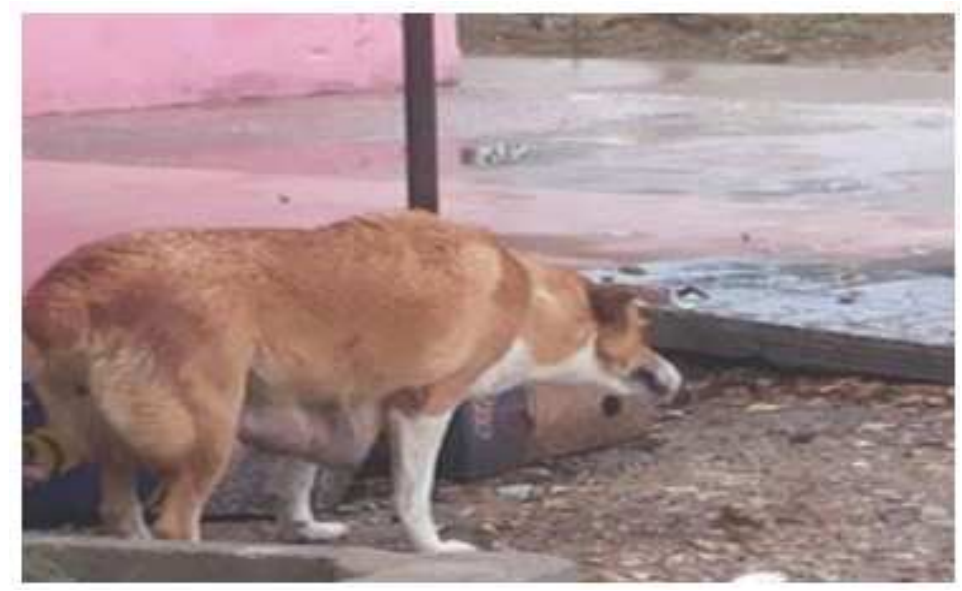

Fig. 7. Large mass of adhesive appearance invading the entire breast chain(Cross-breed)

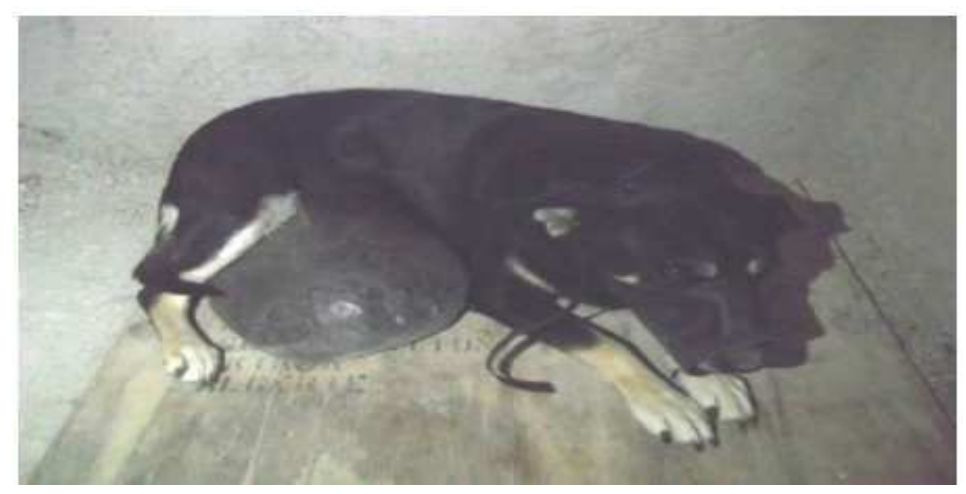

Fig. 8. Large mass (balloon) of ulcerous appearance and soft consistency (Cross-breed)

The mean size of tumors was $5.4 \pm 04 \mathrm{~cm}$ and it was significantly ( $A N O V A, p=0.034$ ) bigger in German shepherd $(6.57 \pm 0.72 \mathrm{~cm})$ followed by Cross breed $(4.62 \pm 0.53 \mathrm{~cm})$ and Caniche $(4.4 \pm 0.45 \mathrm{~cm})$. All bitches had one mammary gland affected and tumors occurred more in the abdominal and thoracic glands $(40.47 \%$ for each) than in inguinal ones (19.04\%). The right mammary glands were more involved than the left ones (61.90\% and $38.09 \%$ respectively) (Table 2 ).

\section{Histopathologic Analysis}

Adequate histologic and cytologic samples were obtained from all MGTs (Fig. 9-15). Distribution and frequencies of their types are summarized in Table 3. 
Table 2. Tumors distribution, size and localization

\begin{tabular}{|c|c|c|c|c|c|}
\hline Province & Breed & $\begin{array}{l}\text { Tumor mass } \\
\text { Biopsy Nbr }\end{array}$ & $\begin{array}{l}\text { Tumor size } \\
\text { Mean } \pm \text { SEM }(\mathrm{cm})\end{array}$ & $\begin{array}{l}\text { Fine needle } \\
\text { aspiration } \mathrm{Nbr}\end{array}$ & $\begin{array}{l}\text { Affected mammary gland } \\
(\mathrm{Nbr}-\mathrm{R} / \mathrm{L})\end{array}$ \\
\hline \multirow[t]{4}{*}{ Constantine } & German shepherd & 5 & $6.6 \pm 1$ & 1 & $\begin{array}{l}\text { A1 (1-L); A2 (1-R); I* (2-R); } \\
\text { T1 (1-R); T2 (1-L) }\end{array}$ \\
\hline & Caniche & 3 & $4.66 \pm 0.88$ & 1 & A1 (1-R); T1 (1-R); I* (2-L) \\
\hline & Cross-breed & 1 & $5.0 \pm 0$ & 1 & $\mathrm{~A} 1 *(2-\mathrm{R})$ \\
\hline & Sub-total & 8 & $5.77 \pm 0.71$ & 3 & \\
\hline \multirow[t]{4}{*}{ Oum El Bouaghi } & German shepherd & 3 & $6.33 \pm 1.76$ & 1 & A2 (1-L); I (1-L); T1* (1-R); T2 (1-R) \\
\hline & Caniche & 2 & $4 \pm 1$ & 1 & A2 (1-R); I* (2-L) \\
\hline & Cross-breed & 2 & $4 \pm 1$ & 1 & A1 (1-R); A2 (1-R); T1* (1-R) \\
\hline & Sub-total & 7 & $5 \pm 0.87$ & 3 & \\
\hline \multirow[t]{4}{*}{ Annaba } & German shepherd & 3 & $5.66 \pm 1.45$ & 1 & A1 (1-R); A2 (1-R); T2* (2-L) \\
\hline & Caniche & 3 & $5 \pm 1.15$ & 1 & A2 (1-R); T1 (1-R); T1 (1-L); T2* (1-L) \\
\hline & Cross-breed & 2 & $4 \pm 1$ & 1 & $\mathrm{~A} 1 *(1-\mathrm{R}) ; \mathrm{T} 1$ (1-R); T2 (1-R) \\
\hline & Sub-total & 8 & $5 \pm 0.68$ & 3 & \\
\hline \multirow[t]{4}{*}{ Skikda } & German shepherd & 3 & $7.66 \pm 2.4$ & 0 & A1 (1-L); A2 (1-L); T2 (1-R) \\
\hline & Caniche & 1 & $3.5 \pm 0.5$ & 2 & $\mathrm{~T} 1$ (1- L); T2* (1-R); I* (1-L) \\
\hline & Cross-breed & 3 & $5.33 \pm 1.2$ & 0 & A1 (1-R); A2 (1-R); T2 (1-R) \\
\hline & Sub-total & 7 & $5.75 \pm 1.08$ & 1 & \\
\hline \multirow[t]{3}{*}{ Overall } & German shepherd & 14 & $6.57 \pm 0.72$ & 3 & $\begin{array}{l}\text { A1 (1-R); A1 (2-L); A2 (2-R); A2 } \\
(2-\mathrm{L}) ; \mathrm{I}^{*}(2-\mathrm{R}) ; \mathrm{I}(1-\mathrm{L}) ; \mathrm{T} 1 *(2-\mathrm{R}) ; \mathrm{T} 2 \\
(2-\mathrm{R}) ; \mathrm{T} 2 *(3-\mathrm{L})\end{array}$ \\
\hline & Caniche & 9 & $4.4 \pm 0.45$ & 5 & $\begin{array}{l}\text { A1 (1-R); A2 (2-R); I* (5-L); T1 } \\
(2-\mathrm{R}) ; \mathrm{T} 1 \text { (2-L); T2* (1-R); T2 (1-L) }\end{array}$ \\
\hline & Cross-breed & 8 & $4.62 \pm 0.53$ & 3 & $\mathrm{~A} 1 *(5-\mathrm{R}) ; \mathrm{A} 2(2-\mathrm{R}) ; \mathrm{T} 1 *(2-\mathrm{R}) ; \mathrm{T} 2$ (2-R) \\
\hline \multicolumn{2}{|c|}{ Total/Overall mean (\%) } & $31(73.81 \%)$ & $5.4 \pm 0.4$ & $11(26.19 \%)$ & $\begin{array}{l}\text { A1 (7-R); A1 (2-L); A2 (6-R); A2 } \\
\text { (2-L); I (2-R); I (6-L); T1 (6-R); T1 } \\
\text { (2-L); T2 (5-R); T2 (4-L) }\end{array}$ \\
\hline
\end{tabular}

Affected mammary glands: A1 (Abdominal cranial); A2 (Abdominal caudal); I (Inguinal); T1 (Thoracic cranial); T2 (Thoracic caudal); R (Right); L (Left); * (Fine needle aspiration

Table 3. Histological types of mammary tumors and their distribution

\begin{tabular}{|c|c|c|c|c|c|c|c|c|c|c|c|c|}
\hline \multirow[b]{2}{*}{ Province } & \multirow[b]{2}{*}{ Breed } & \multicolumn{5}{|c|}{ Malignant ' $\mathrm{M}$ ' tumors $\mathrm{Nbr}(\%)$} & \multicolumn{3}{|c|}{ Benign 'B' tumors Nbr (\%) } & \multicolumn{3}{|c|}{ Dysplasia 'D' Nbr (\%) } \\
\hline & & $\begin{array}{l}\text { Type } 1 \\
\text { (EC) }\end{array}$ & $\begin{array}{l}\text { Type } 2 \\
\text { (SC) }\end{array}$ & $\begin{array}{l}\text { Type } 3 \\
\text { (MS) }\end{array}$ & $\begin{array}{l}\text { Type } 4 \\
\text { (CC) }\end{array}$ & $\begin{array}{l}\text { Type } 5 \\
\text { (MCT) }\end{array}$ & $\begin{array}{l}\text { Type } \\
\text { A (CA) }\end{array}$ & $\begin{array}{l}\text { Type } \\
\text { B (BMT) }\end{array}$ & $\begin{array}{l}\text { Type } \\
\text { C (BMT) }\end{array}$ & $\mathrm{BH}$ & FM & $\mathrm{OM}$ \\
\hline \multirow[t]{4}{*}{ Constantine } & German shepherd & $0(00)$ & $0(00)$ & $1(16.66)$ & $0(00)$ & $1(16.66)$ & $1(16.66)$ & $0(00)$ & $2(33.33)$ & $0(00)$ & $1(16.66)$ & $0(00)$ \\
\hline & Caniche & $0(00)$ & $0(00)$ & $0(00)$ & $0(00)$ & $0(00)$ & $2(50.00)$ & $0(00)$ & $0(00)$ & $0(00)$ & $1(25.00)$ & $1(25.00)$ \\
\hline & Cross-breed & $1(50.00)$ & $0(00)$ & $0(00)$ & $0(00)$ & $0(00)$ & $0(00)$ & $0(00)$ & $0(00)$ & $0(00)$ & $0(00)$ & $1(50.00)$ \\
\hline & Sub-total & $1(8.33)$ & $0(00)$ & $1(8.33)$ & $0(00)$ & $1(8.33)$ & $3(25.00)$ & $0(00)$ & $2(16.66)$ & $0(00)$ & $2(16.66)$ & $2(16.66)$ \\
\hline \multirow[t]{4}{*}{ Oum El Bouaghi } & German shepherd & $0(00)$ & $0(00)$ & $1(25.00)$ & $0(00)$ & $0(00)$ & $1(25.00)$ & $1(25.00)$ & $0(00)$ & $1(25.00)$ & $0(00)$ & $0(00)$ \\
\hline & Caniche & $0(00)$ & $0(00)$ & $0(00)$ & $0(00)$ & $0(00)$ & $1(33.33)$ & $1(33.33)$ & $1(33.33)$ & $0(00)$ & $0(00)$ & $0(00)$ \\
\hline & Cross-breed & $1(33.33)$ & $0(00)$ & $1(33.33)$ & $0(00)$ & $0(00)$ & $0(00)$ & $1(33.33)$ & $0(00)$ & $0(00)$ & $0(00)$ & $0(00)$ \\
\hline & Sub-total & $1(10.00)$ & $0(00)$ & $2(20.00)$ & $0(00)$ & $0(00)$ & $2(20.00)$ & $3(30.00)$ & $1(10.00)$ & $1(10.00)$ & $0(00)$ & $0(00)$ \\
\hline \multirow[t]{4}{*}{ Annaba } & German shepherd & $1(25.00)$ & $1(25.00)$ & $0(00)$ & $0(00)$ & $1(25.00)$ & $0(00)$ & $0(00)$ & $0(00)$ & $1(25.00)$ & $0(00)$ & $0(00)$ \\
\hline & Caniche & $0(00)$ & $0(00)$ & $0(00)$ & $1(25.00)$ & $0(00)$ & $0(00)$ & $1(25.00)$ & $1(25.00)$ & $1(25.00)$ & $0(00)$ & $0(00)$ \\
\hline & Cross-breed & $0(00)$ & $0(00)$ & $0(00)$ & $0(00)$ & $0(00)$ & $0(00)$ & $0(00)$ & $2(66.66)$ & $0(00)$ & $0(00)$ & $1(33.33)$ \\
\hline & Sub-total & $1(9.09)$ & $1(9.09)$ & $0(00)$ & $1(9.09)$ & $1(9.09)$ & $0(00)$ & $1(9.09)$ & $3(27.27)$ & $2(18.18)$ & $0(00)$ & $1(9.09)$ \\
\hline \multirow[t]{4}{*}{ Skikda } & German shepherd & $0(00)$ & $0(00)$ & $0(00)$ & $0(00)$ & $0(00)$ & $0(00)$ & $1(33.33)$ & $0(00)$ & $1(33.33)$ & $0(00)$ & $1(33.33)$ \\
\hline & Caniche & $0(00)$ & $1(33.33)$ & $0(00)$ & $1(33.33)$ & $0(00)$ & $0(00)$ & $1(33.33)$ & $0(00)$ & $0(00)$ & $0(00)$ & $0(00)$ \\
\hline & Cross-breed & $0(00)$ & $0(00)$ & $0(00)$ & $0(00)$ & $1(33.33)$ & $0(00)$ & $0(00)$ & $0(00)$ & $0(00)$ & $2(66.66)$ & $0(00)$ \\
\hline & Sub-total & $0(00)$ & $1(11.11)$ & $0(00)$ & $1(11.11)$ & $1(11.11)$ & $0(00)$ & $2(22.22)$ & $0(00)$ & $1(11.11)$ & $2(22.22)$ & $1(11.11)$ \\
\hline \multirow[t]{5}{*}{ Overall } & German shepherd & $1(5.88)$ & $1(5.88)$ & $2(11.76)$ & $0(00)$ & $2(11.76)$ & $2(11.76)$ & $2(11.76)$ & $2(11.76)$ & $3(17.64)$ & $1(5.88)$ & $1(5.88)$ \\
\hline & Caniche & $0(00)$ & $1(7.14)$ & $0(00)$ & $2(14.28)$ & $0(00)$ & $3(21.42)$ & $3(21.42)$ & $2(14.28)$ & $1(7.14)$ & $1(7.14)$ & $1(7.14)$ \\
\hline & Cross-breed & $2(18.18)$ & $0(00)$ & $1(9.9)$ & $0(00)$ & $1(9.9)$ & $0(00)$ & $1(9.9)$ & $2(18.18)$ & $0(00)$ & $2(18.18)$ & $2(18.18)$ \\
\hline & Total/Type & $3(7.14)$ & $2(4.76)$ & $3(7.14)$ & $2(4.76)$ & $3(7.14)$ & $5(11.90)$ & $6(14.28)$ & $6(14.28)$ & $4(9.52)$ & $4(9.52)$ & $4(9.52)$ \\
\hline & Total/'M'; 'B'; 'D' & $13(30.95)$ & & & & & $17(40.47)$ & & & $12(28.57)$ & & \\
\hline
\end{tabular}
(Epidermoidcarcinoma+Complexadenoma); CA: Complexadenoma; BMT: Benign mixed tumor; BCT: Benigncomplextumor (Complexadenoma+Benign mixed tumor); BH: Benign hyperplasia; FM: Fibrocysticmastopathy; OM: Osteo-mammary 


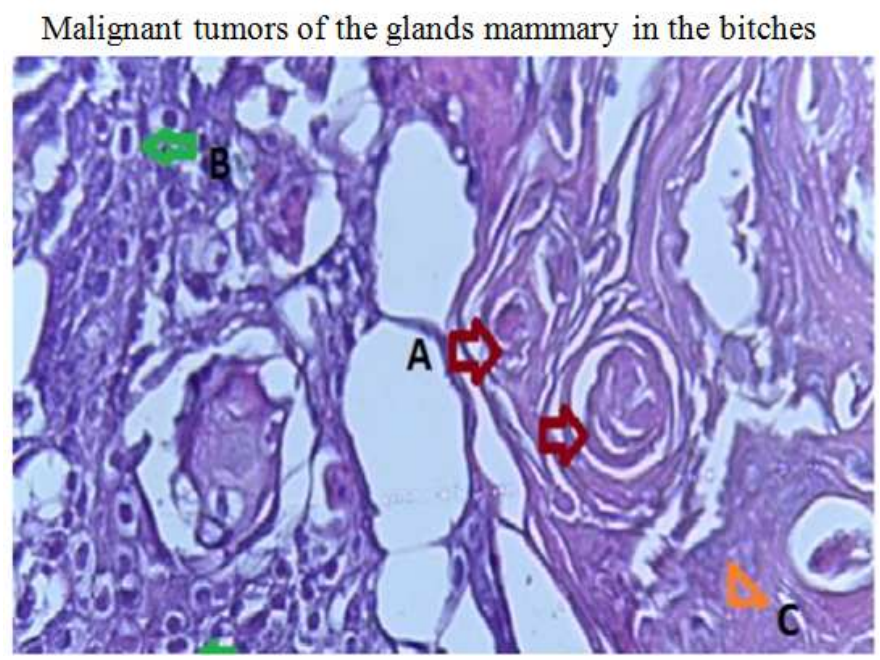

Fig. 9. Squamous cell carcinoma: is composed solely of squamous epithelium ( metaplasia and neoplastic transformation Histologically, the neoplasm is identical to those that occur in the skin. Islands and cords of epithelial cells are seen with the formation of keratin pearls (A) Keratin pearls (B) Squamous epithelium (C) Fibrous Stroma

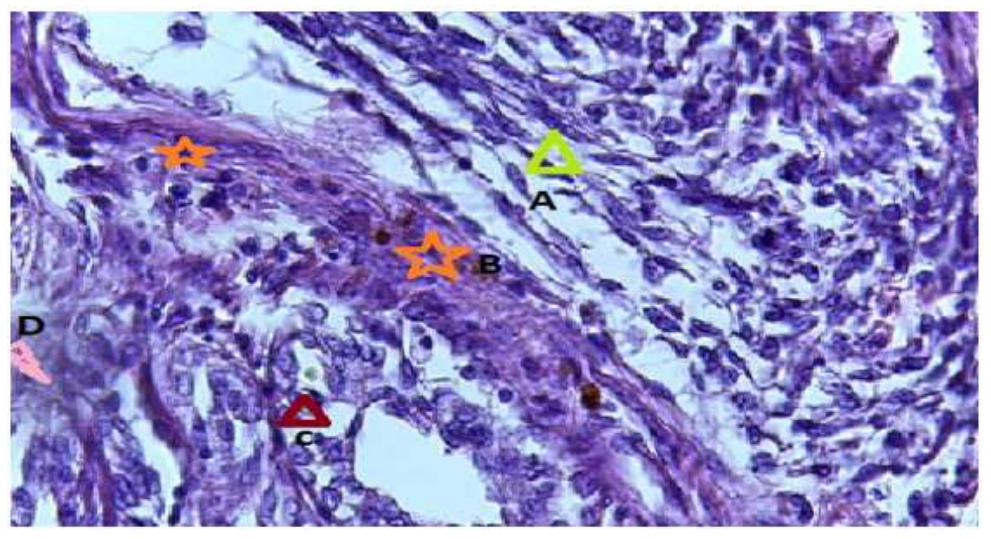

Fig. 10. Carcinoma-spindle cell Note the intimate association of the neoplastic spindle cells with the islands of tubular epithelium (A) Cells and nuclei are large and fusiform, (B) islands and cords of epithelial cells, often with a direct association with areas of tubular carcinoma (C) Preexisted normal gland tubule (D) Fibrovascular stroma
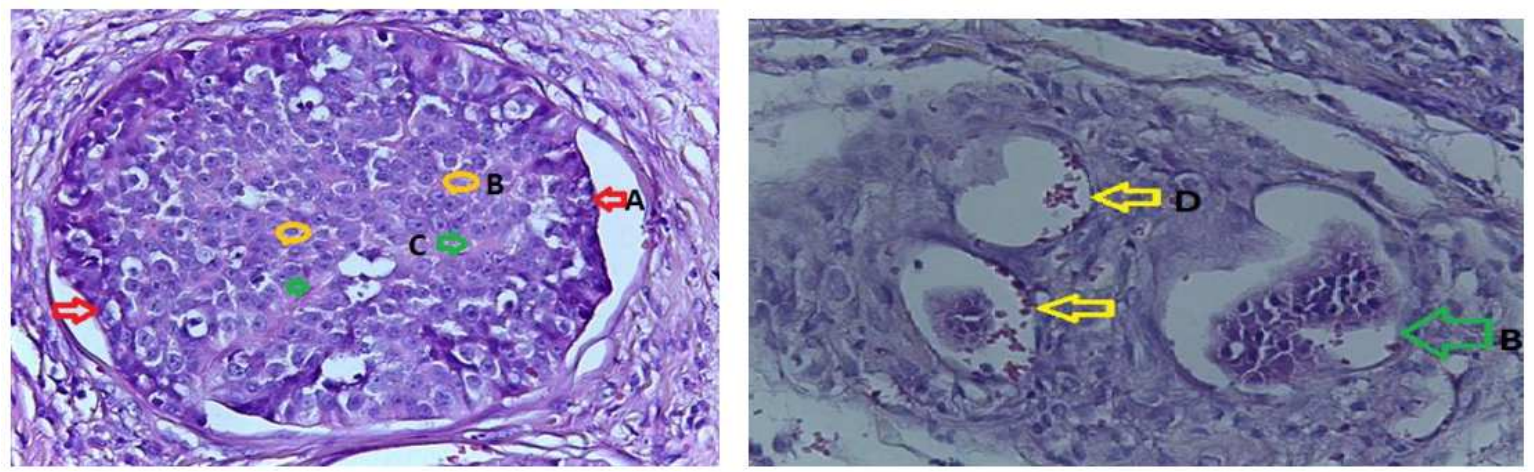

Fig. 11. Cribriform carcinoma: which is uncommon, is characterized by the proliferation of a population of neoplastic epithelial cells forming a sievelike arrangement that surround small lumina. (A) Neoplastic cells vary from columnar to polygonal and often have scant homogeneous eosinophilic cytoplasm (B) Population of neoplastic epithelial cells forming a sievelike (C) Small lumina (D) Lymphatic Embole signs presence of metastasis 


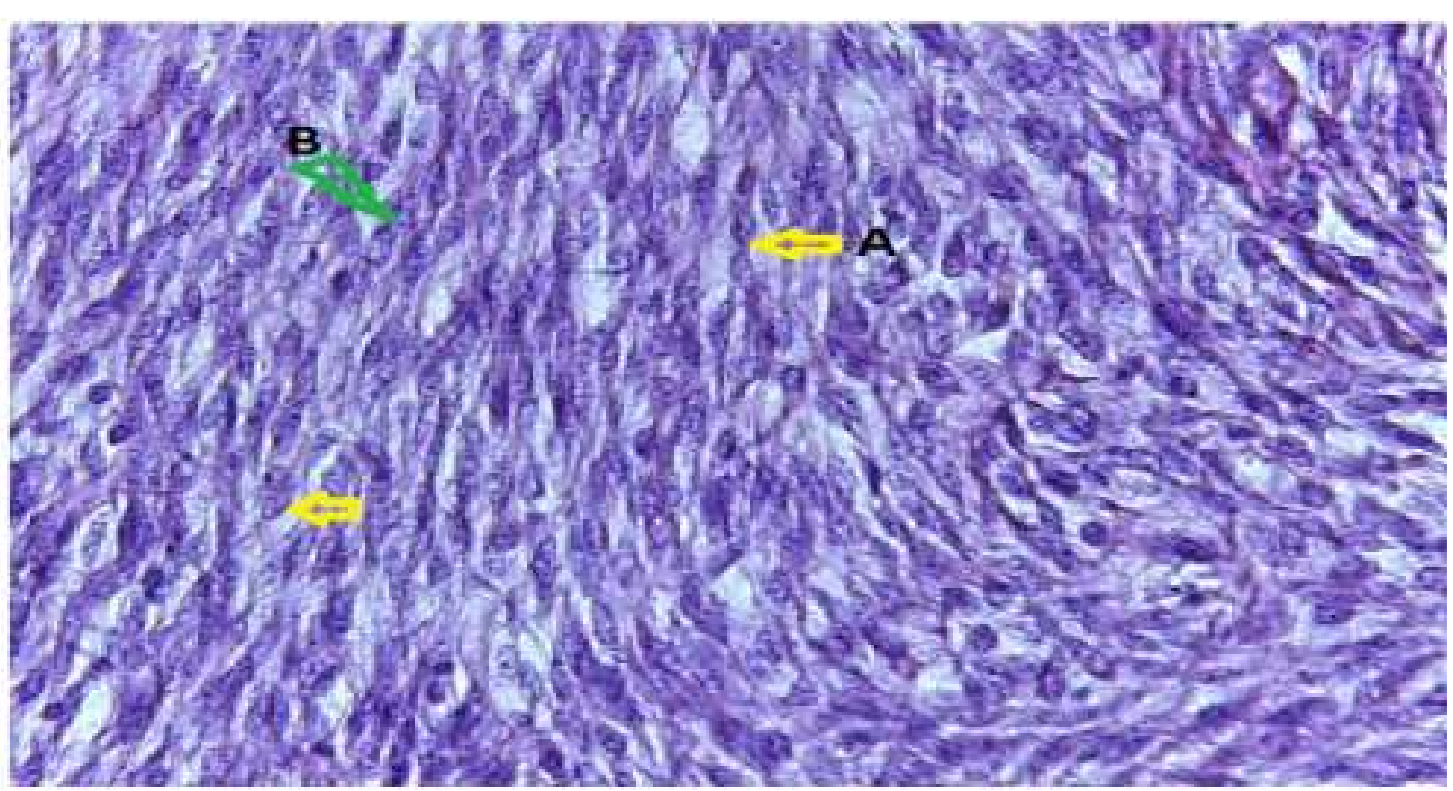

Fig. 12. Sarcoma mammary canine: The remnants of mammary ducts are surrounded by the neoplastic spindle cells (A) Proliferation of fusiform cells with a distinctly interwoven Pattern, (B) Nuclei that contain finely stippled chromatin and variably

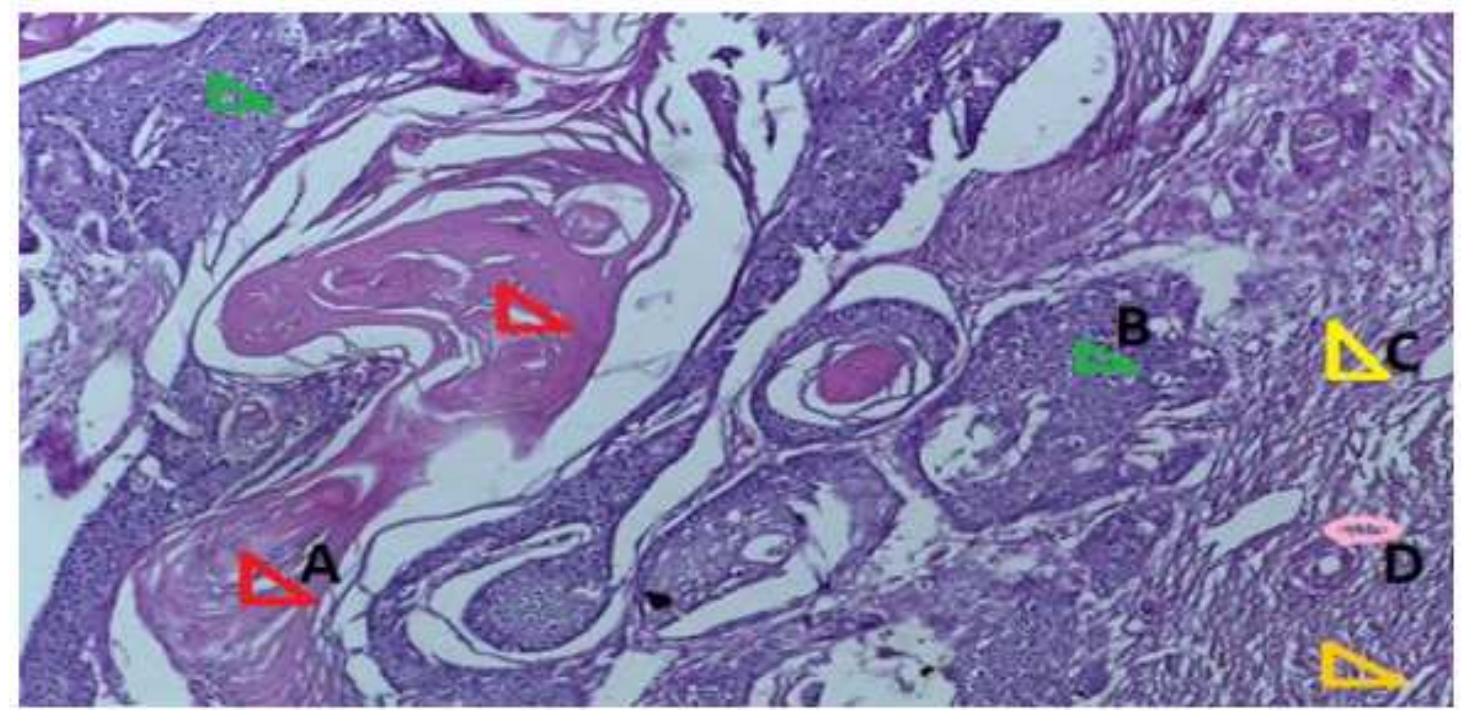

Fig. 13. Squamous cell carcinoma Arising in a Complex Adenoma (A) Keratin to nofilaments (B) Foci of carcinoma cells (C) Stroma myxoide of the complex adenoma (D) Cells arranged in tubules of the benign counterpart (Complex Adenoma)

According to histopathological classification, $17 / 42(40.47 \%)$ tumors were diagnosed as benign, 13 $(30.95 \%)$ as malignant and $12(28.57 \%)$ as dysplasia with no significant difference $\left(X^{2}, p=0.54\right)$ between their rates of occurrence.

Benign neoplasms were mostly represented by both benign mixed tumors and benign complex tumors and less by complex adenoma. For the malignant group, epidermoid carcinoma, mammary sarcoma and malignant complex tumors (epidermoid carcinoma + complex adenoma) were the most encountered, while spindle cell sarcoma and cribriform carcinoma were less frequent lesions. Osteo-mammary dysplasia, benign hyperplasia and fibrocystic mastopathy were equally diagnosed dysplasias. There was no association between the neoplasm category (malignant, benign or dysplasia) and the age of animals (ANOVA, $p=0.9)$, their breed $\left(X^{2}, p=0.68\right)$ or their region of origin $\left(X^{2}, p=0.4\right)$. 
Benin tumors of the glands mammary in the bitches

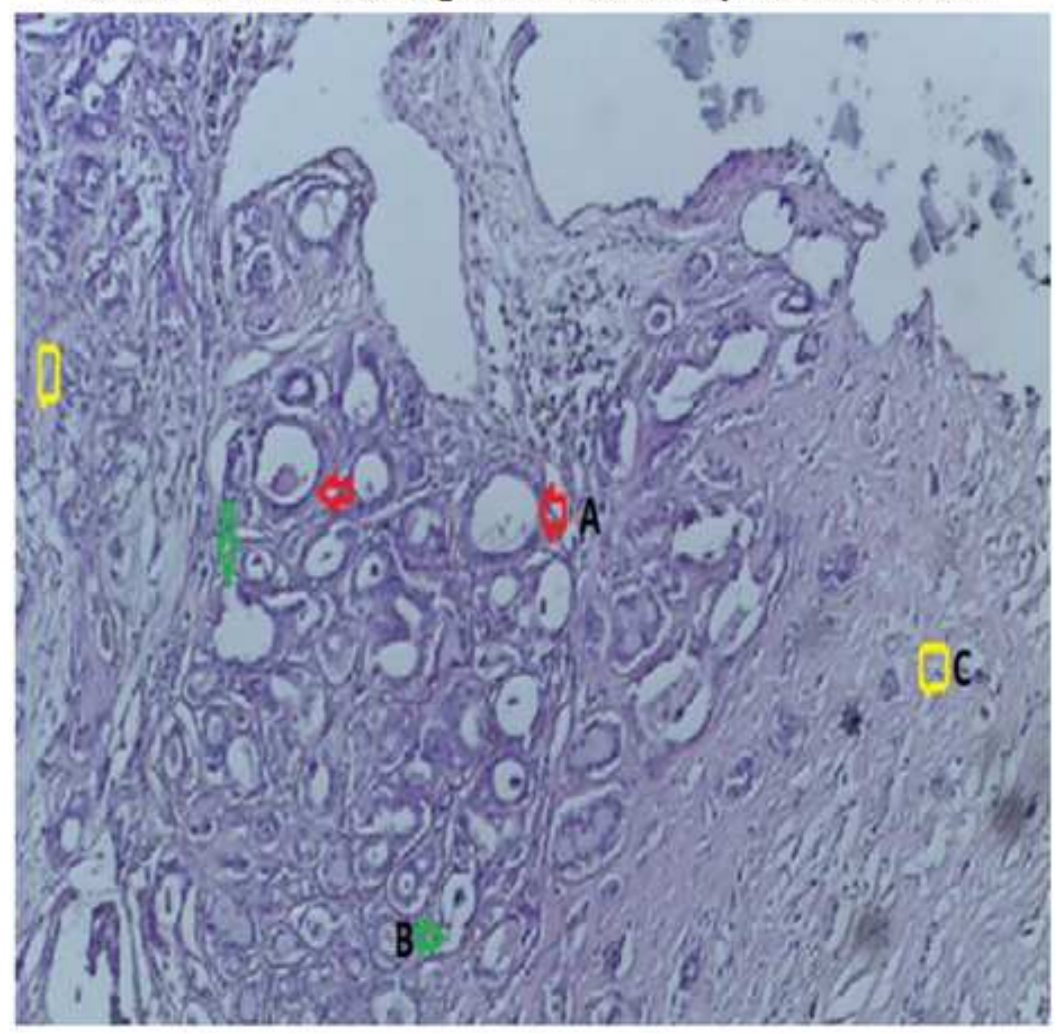

Fig. 14. Adenoma, mammary gland, canine. The ducts are lined by a uniform population of columnar cells (A) Lesions composed of cells arranged in tubules that occasionally contain an amorphous amphophilic secretion. (B) Tubules are lined by a single layer of cuboidal to columnar cells with a moderate amount of eosinophilic cytoplasm (C) Fibrovascular stroma (myxoide)

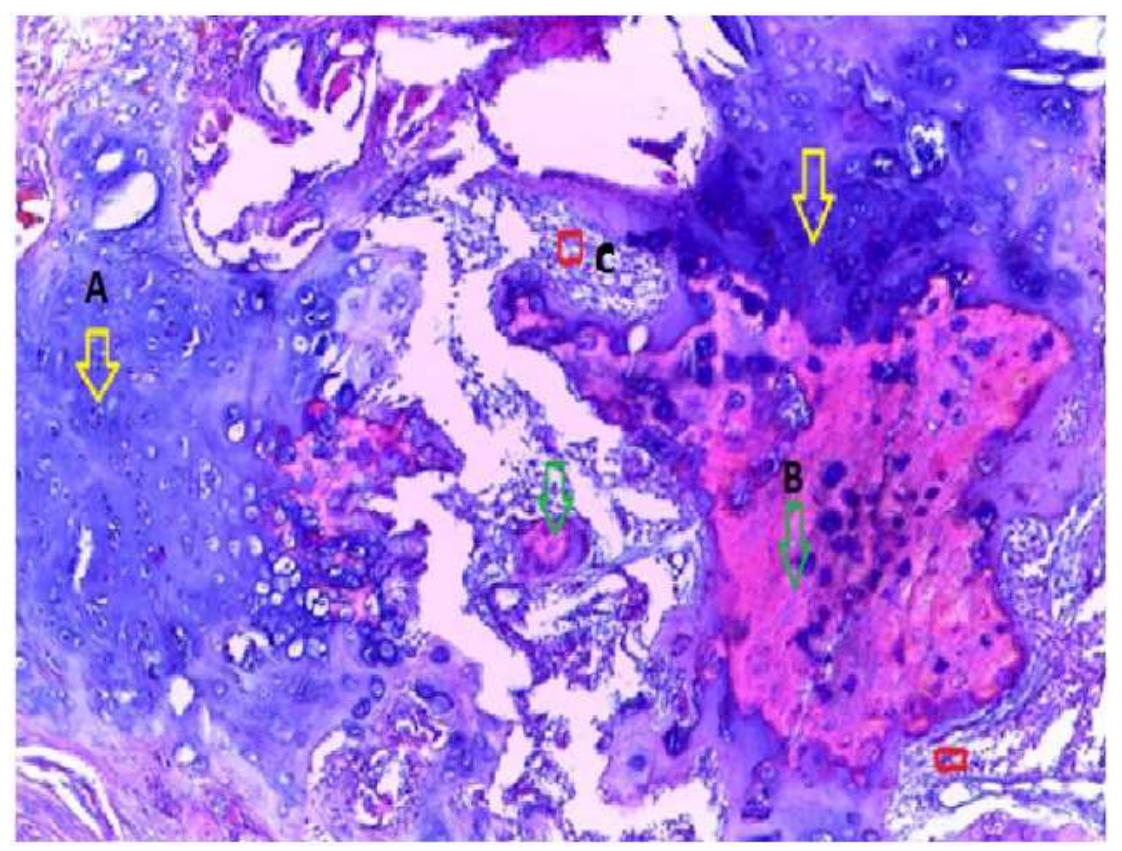

Fig. 15. Benign mixed tumor, mammary gland, canine. Note the ductal and myoepithelial cells with foci of chondroid and osseous differentiation. (A) Multifocally, areas of cartilage (B) Multifocally, areas of the bone (C) Osseous marrow 


\section{Discussion}

In dogs and all over the world, a big number of deaths are due to cancers development and complications (MacEwen and Withrow, 1996). However, rare studies have been undertaken regarding the epidemiological status of neoplasms in the canine population in Algeria and especially those affecting the mammary gland. Thus, the current study brings some insights on the frequency and the types of tumors affecting this gland in female dogs in our country. The prevalence we have recorded is lower than that reported in Mexico (24\%) (Fajardo et al., 2013) and India (39.87\%) (Dhami and Tank, 2010), but it is higher than that recorded in Grenada-West Indies $(10.8 \%)$ (Bhaiyat et al., 2013). Differences between regions and countries may be related to several factors such as animal body size and diet, spaying practices and hormones usage and especially pollutants. Obesity and high-fat diets have been connected to an increased incidence of MGTs in dogs (Sonnenschein et al., 1991; Alenza et al., 1998). In a review published by Rudel et al. (2017) about 216 chemicals were identified to be associated with increases in mammary gland neoplasms. They comprise industrial chemicals, chlorinated solvents, products of combustion, pesticides, dyes, radiation, drinking water disinfection products, pharmaceuticals and hormones, natural products and research chemicals. This may explain in part the high prevalence we recorded in littoral provinces (which may be more polluted) as compared with inland ones.

The occurrence risk of MGTs in intact bitches is four to seven folds higher as compared to those neutered at 2 years old or earlier (Alenza et al., 2000; Sorenmo, 2003). Female dogs spayed prior to their first estrus cycle are very less predisposed to this problem (Dhami and Tank, 2010). If the dog is neutered later than after the second estrus cycle, the risk for developing malignant MGTs is as high as in intact bitches and the risk for benign MGTs is reduced by ovario-hysterectomy even at a later age (Misdorp, 1991). Sexual hormones are known to make some mammary cells losing their controlled growth and expose them to increased risk of mutation and malignant transformation within an environmental carcinogenic pressure (Sorenmo et al., 2000). Rutteman et al. (2000) reported about $50 \%$ of malignant primary tumors to be positive for estrogen, progesterone and prolactin receptors. On the other hand, it is worth mentioning that in rare cases $(1.3 \%)$ mammary tumors can also be observed in male dogs (Simon et al., 1996).

A genetic predisposition has been suggested since certain breeds were described to have an increased risk to develop MGTs (Kurzman and Gilbertson, 1986; Yamagami et al., 1996). Various studies regarding the impact of breed on the development of mammary neoplasms had been undertaken. Pomeranian and German shepherd were breeds that develop more mammary neoplasms (Dhami and Tank, 2010) which are in complete contrast with our findings since we observed fewer cases in this breed. Alenza et al. (2000), reported no breed predisposition to MGTs in dogs, but it seems that these health disorders are more common in pure breeds than in mixed breeds.

Mammary neoplasms are rarely seen in young dogs (less than 3 years of age) (Egenvall et al., 2005). In agreement with our findings, it has been observed that the incidence increases with age and reaches the maximum between 9 and 11 years; however, some breeds develop MGTs at a younger age (Moe, 2001). The increasing frequency of MGTs with age could be related to constant accumulation of somatic mutations which could conduct to the development of cancer (Vegad, 2007). Sowbharenya et al. (2016) gave more details on the effect of age on the occurrence of these neoplasms. In their findings, highest incidence was seen in the age group of three to six years, followed by six to nine years and 9-12 years; whereas the least incidence was observed between zero to three years and $12-15$ years.

In regard to neoplasms types, mammary dysplasia as usually occur in dogs aged of 2 to 4 years old, benign tumors before 5 years and after 6 years the diagnosed tumors are more likely to be malignant (Alenza et al., 2000). Sorenmo et al. (2009) suggest that canine mammary tumors progress from benign to malignant and that malignant tumor may be the final phase of a histological continuum.

Even though, small tumors can be malignant and large ones may be benign, a correlation had been proved between the MGTs size and the rate of metastasis (malignancy) and the reduced life expectation of animals. Favorable course of the disease has been described among animals with tumors smaller than $5 \mathrm{~cm}$ in diameter (Magnol et al., 1998).

Pawar et al. (2015) in their investigation have found $13.3 \%$ of mammary neoplasms to be benign (Cystic adenoma and Mixed adenoma) and $86.6 \%$ to be malignant (Adenocarcinoma, Mixed type, Scirrhous type, Duct carcinoma and Fibrosarcoma) in the canine population of Mumbai (India). The Norwegian Canine Cancer Register reported a crude incidence of malignant MGTs of $53.3 \%$ in female dogs of any breed (Moe, 2001). The results of these studies are in contrast with ours since we described benign neoplasms as a majority. Peña et al. (2013) found a high number of complex tumors and adenosquamous carcinoma among MGTs; while Santos et al. (2013) found a greater number of solid and complex carcinomas.

As in our findings, Sowbharenya et al. (2016) found solitary involvement of glands to be frequent especially in the right side as compared to the left; however, they reported inguinal pair and cranial abdominal pair of mammary glands to be the most commonly affected, followed by caudal abdominal and thoracic mammary glands. The involvement was higher in the inguinal, 
the abdominal and the thoracic glands respectively (Sontas et al., 2009). This could be attributed to greater proliferative changes in inguinal mammary glands in response to estrogen (Kumar et al., 2011) and additionally, most caudal pairs of mammary glands include the greater part of mammary tissue and are prone to mechanical trauma (Rutteman et al., 2000).

In conclusion, the results of the current study prove that MGTs are frequent lesions in bitches of four provinces of the northeastern Algeria. More details are presented on their prevalence and histopathologic types; however, supplementary epidemiological investigations are needed to determine the risk factors that may be implicated in the initiation and evolution of these disorders. These data may be of a great usefulness in elucidating some of human cancers epidemiology, since dogs are the animals that share the same environment with humans and some of their tumors (particularly those affecting the mammary gland) evolve in same way as some human neoplasms (the breast cancer for instance).

\section{Acknowledgement}

The authors are grateful to all the persons who helped us to carry out this work.

\section{Author's Contributions}

Zahra Gabli: This work was carried out in collaboration between all authors. The first author assisted all the steps of this work: He designed the study, assisted sample collection, data analysis and manuscript preparation.

Leila Beddar: Supervised the study, coordinated the data-analysis and contributed to the writing of the manuscript.

Amir Agabou: Participated actively in data analyses and interpretation, writing the paper and critically revising it.

Zouhir Djerrou: Contributed in drafting the manuscript and reviewing it critically.

Edouard Reyes-Gomez: Performed histopathological findings, analyzed and interpreted the results, coordinated the data-analysis and contributed to the writing of the manuscript.

\section{Ethics}

This article is original and contains unpublished material. The corresponding author confirms that no ethical issues involved.

\section{References}

Alenza, D.P., L. Pena, D.N. Castillo and I.A. Nieto, 2000. Factors influencing the incidence and prognosis of canine mammary tumors. J. Small Anim. Pract., 41: 287-291.
Alenza, D.P., G.R. Rutteman, L. Pena, A.C. Beynen and P. Cuesta, 1998. Relation between habitual diet and canine mammary tumors in a case-control study. J. Vet. Intern. Med., 12: 132-139.

Bhaiyat, M.I., A. Chikweto, K.P. Tiwari, C. DeAllie and R.S. Pawaiya et al., 2013. A retrospective study of canine tumors in Grenada, West Indies. Adv Anim. Vet. Sci., 1: 134-139.

Dhami, M.A. and P.H. Tank, 2010. Studies on epidemiological aspects of canine mammary gland tumours in Gujarat. Indian J. Field Vet., 5: 5-10.

Egenvall, A., B.N. Bonnett, P. Ohagen, P. Olson and A. Hedhammar et al., 2005. Incidence of and survival after mammary tumors in a population of over 80000 insured female dogs in Sweden from 1995 to 2002. Prev. Vet. Med., 69: 109-127.

Fajardo, A.R., A. Alpízara, L.S. Péreza, J.S. Martíneza and E. Córdovab, 2013. Prevalence of tumors in dogs from the municipality of Toluca, México, from 2002 to 2008. Arch. Med. Vet., 45: 305-309.

Geraldes, M., F. Gartner and F. Scmitt, 2000. Immunohistochemical study of hormonal receptors and cell proliferation in normal canine mammary glands and spontaneous mammary tumours. Vet. Rec., 146: 403-406.

Hampe, J.F. and W. Misdorp, 1974. Tumours and dysplasias of the mammary gland. Bull World Health Organ., 50: 111-133.

Henry, C.J., 2014. Mammary Cancer. In: Current Veterinary Therapy XV, Bonagura, J.D. and D.C. Twedt (Eds.), Saunders Elsevier, St. Louis, Missouri, USA, pp: 375-380.

Kumar, K.R.A, G.V.S. Rao and C. Balachandran, 2011. Incidence, cytology, gross pathology and histopathology of mammary tumors in dogs of Chennai. Int. J. Pharm. Biol. Sci., 12: 399-405.

Kumar, P., R. Kumar, R.S. Pawaiya and M.B. Puttaswamy, 2010. Diagnostic significance of mitotic index and AgNOR count in canine mammary tumours. Braz. J. Vet. Path., 3: 41-45.

Kurzman, I.D. and S.R. Gilbertson, 1986. Prognostic factors in canine mammary tumors. Seminars Vet. Med. Surgery J., 1: 25-32.

MacEwen, E.G. and S. Withrow, 1996. Tumors of the mammary gland. Small Animal Oncol.

Magnol, J.P., T. Marchal, F. Delisle, P. Devauchelle and C. Fournel, 1998. Les tumeurs mammaires. In: Cancérologie Clinique Du Chien. Saint-Pierre Le Palud, France, pp: 217-229.

Misdorp, W., 1991. Progestagens and mammary tumours in dogs and cats. Acta Endocrinol., 125: 27-31.

Misdorp, W., 2002. Tumors of the Mammary Gland. In: Tumors in Domestic Animals, Meuten D.J. (ed.), Iowa State Press, Ames, USA, pp: 575-606.

Moe, L., 2001. Population-based incidence of mammary tumours in some dog breeds. J. Reprod Fertil., 57: 439-443. 
Pawar, Y., D. Kadam, G. Khandekar and R. Nehte, 2015. Gross and cytological evaluation of canine spontaneous mammary neoplasms and its correlation with histopathology and morphometric analysis. Int. J. Vet. Sci., 4: 104-110.

Peña, L., P.J. De Andrés, M. Clemente, P. Cuesta and M.D. Pérez-Alenza, 2013. Prognostic value of histological grading in noninflammatory canine mammary carcinomas in a prospective study with two-year follow-up: Relationship with clinical and histological characteristics. Vet. Path., 50: 94-105.

Rudel, R.A., K.R. Attfield, J.N. Schifano and J.G. Brody, 2007. Chemicals causing mammary gland tumors in animals signal new directions for epidemiology, chemicals testing and risk assessment for breast cancer prevention. Cancer, 109: 2635-2666.

Rutteman, G.R. and W. Misdorp, 1993. Hormonal background of canine and feline mammary tumours. J. Reprod Fertil., 47: 483-487.

Rutteman, G.R., S.J. Withrow and E.G. MacEwen, 2000. Tumors of the Mammary Gland. In: Small Animal Clinical Oncology, Winthrow S.J. and E.G. MacEwen (Eds.), Philadelphia, WB Saunders, pp: 450-467.

Santos, A.A., C.C. Lopes, J.R. Ribeiro, L.R. Martins and J.C. Santos et al., 2013. Identification of prognostic factors in canine mammary malignant Tumours: A multivariable survival study. BMC Vet. Res., 9: 1-11.

Simon, D., P. Goronzy, I. Stephan, L.A. Meyer and M. Aufderheide et al., 1996. Mammary Tumours in dogs: Investigation of the occurrence and course of the disease. Prakt Tierarzt., 77: 771-782.

Sonnenschein, E.G., L.T. Glickman, M.H. Goldschmidt and L.J. McKee, 1991. Body conformation, diet and risk of breast cancer in pet dogs: A case-control study. Am. J. Epidemiol., 133: 694-703.
Sontas, B.H., H. Ozyogurtcub, A. Gurelb and H. Ekicia, 2009. Evaluation of clinical and pathological characteristics of 155 canines with mammary tumours: A retrospective study. Arch. Med. Vet., 41: 53-59.

Sorenmo, K., 2003. Canine mammary gland tumors. J. Small Anim. Pract., 33: 573-596.

Sorenmo, K., V.M. Kristiansen, M.A. Cofone, F.S. Shofer and A.M. Breen et al., 2009. Canine mammary gland Tumours: A histological continuum from benign to malignant; clinical and histopathological evidence. Vet. Compare Oncol., 7: 162-172.

Sorenmo, K., F.S. Shofer and M.H. Goldschmidt, 2000. Effect of spaying and timing of spaying on survival of dogs with mammary carcinoma. J. Vet. Intern Med., 14: 266-270.

Sowbharenya, C., S. Dharmaceelan, A. Kumaresan and M. Subramanian, 2016. Incidence and glandular distribution of canine mammary neoplasms. Indian Vet. J., 93: 27-28.

Sundaram, S.G. and J.A. Milner, 1993. Impact of organo sulfur compounds in garlic on canine mammary tumor cells in culture. Cancer Lett., 74: 85-90.

Vail, D.M. and E.G. MacEwen, 2000. Spontaneously occurring tumors of companion animals as models for human cancer. Cancer Invest., 18: 781-792.

Vegad, J.L., 2007. Veterinary General Pathology. 2nd Edn., International, Book Distributing, Co, UP, India, pp: 290.

Yamagami, T., T. Kobayashi, K. Takahashi and M. Sugiyama, 1996. Prognosis for canine malignant mammary tumors based on TNM and histologic classification. J. Vet. Med. Sci., 58: 1079-1083. 